\title{
Glutamine Synthesis Regulates Sucrose Catabolism in Neurospora crassa
}

\author{
By GEORGINA HERNÁNDEZ AND JAIME MORA* \\ Centro de Investigación sobre Fijación de Nitrógeno, Universidad Nacional Autónoma de México, \\ Cuernavaca, Mor., Mexico
}

(Received 30 April 1986)

\begin{abstract}
The effect of glutamine synthesis on sucrose metabolism in Neurospora crassa was studied. Different inhibitors of glutamine synthetase were used to inhibit glutamine synthesis in mutants having a low ammonium assimilation capacity. Sucrose utilization was impaired, as indicated by a lower concentration and synthesis of intermediates of the tricarboxylic acid cycle and reduced release of $\mathrm{CO}_{2}$. We propose that a coordinated regulation of carbon and nitrogen utilization is achieved through sensing of the carbon and nitrogen flows through glutamine synthesis, mediated by changes in the intracellular content of ATP, which is reduced as a consequence of glutamine synthesis.
\end{abstract}

\section{INTRODUCTION}

Carbon and nitrogen metabolism interact in the first instance in the reactions of ammonium assimilation. Carbon compounds, energy and reducing power are required for glutamate and glutamine synthesis. In Neurospora crassa glutamate can be synthesized through the participation of two different enzymes, glutamate dehydrogenase (GDH) (EC 1.4.1.4), NADPH dependent, which synthesizes glutamate from 2-oxoglutarate and ammonium (Fincham, 1950; Hernández et al., 1983) and glutamate synthase (GOGAT) (EC 1.4.1.14), NADH dependent, which gives two molecules of glutamate from glutamine and 2-oxoglutarate (Hummelt \& Mora, 1980a,b). Glutamine synthetase (GS) (EC 6.3.1.2) requires ATP and in $N$. crass $a$ it is found in two different oligomeric forms composed of $\alpha$ and $\beta$ monomers respectively (Dávila et al., 1980).

Carbon and nitrogen metabolism also interact in the metabolic steps related to the distribution of nitrogen from glutamate and glutamine into several biosynthetic pathways. In $N$. crassa the nitrogen from glutamine is distributed by the enzymes of the $\omega$-amidase pathway as well as by transamidation. Glutamine transaminase synthesizes different amino acids and $\omega$ amidase hydrolyses the resulting 2-oxoglutaramate to 2-oxoglutarate and ammonium (Calderón et al., 1985). The ammonium released by the $\omega$-amidase pathway is assimilated not only by GDH but also by GS, thus leading to the operation of a glutamine cycle in which this amino acid is continually degraded and resynthesized (Calderón et al., 1985; Calderón \& Mora, 1985). GOGAT also participates in the distribution of the nitrogen from glutamine (Calderón \& Mora, 1985).

The regulation by the nitrogen source of the enzymes that synthesize glutamate or glutamine (Hernández et al., 1983; Vichido et al., 1978; Quinto et al., 1977; Sánchez et al., 1978) and the participation of these enzymes in different ammonium assimilation pathways in $N$. crassa (Lara et al., 1982) have been reported. There have also been reports on the regulation of GS and of GDH by the carbon source in $N$. crassa and other micro-organisms (Ferguson \& Sims, 1974a, $b$; Hemmings, 1978; Kapoor \& Grover, 1970). Mora et al. (1980) reported that when mycelium of

Abbreviations: GDH, glutamate dehydrogenase; GOGAT, glutamate synthase; GS, glutamine synthetase; MS, methionine sulphoximine. 
$N$. crassa was deprived of the carbon source, the GS was degraded; they proposed that this could be a regulatory mechanism to conserve energy. However, despite the cost, in terms of carbon skeletons, reducing power and ATP, of the ammonium assimilation reactions, nothing is known about the effect of glutamine synthesis on carbon metabolism. We therefore looked for an effect of glutamine synthesis on sucrose metabolism in $N$. crassa.

\section{METHODS}

Strains. The Neurospora crassa wild-type strain 74A, the GDH-deficient mutant am-I (GDH $\left.{ }^{-}\right)$and the GS partial auxotroph $g l n-I a\left(G^{ \pm}\right)$were from the Fungal Genetics Stock Center (Humboldt State University Foundation, Arcata, Calif., USA). The double mutant $a m-1 ; g l n-1 a\left(\mathrm{GDH}^{-} ; \mathrm{GS}^{ \pm}\right)$was from the collection of $\mathrm{J}$. Mora.

Growth conditions. Batch cultures of $N$. crassa were grown at $37^{\circ} \mathrm{C}$ on Vogel minimal medium (N) (Vogel, 1964) containing $1.5 \%(\mathrm{w} / \mathrm{v})$ sucrose. At this growth temperature a higher GS activity allowed a higher growth rate in all the strains used and allowed growth of the glutamine auxotroph (GS ${ }^{ \pm}$) on glutamate (Dávila et al., 1978). Other nitrogen sources used in place of or in addition to ammonium nitrate are stated in the text. Growth was measured as described previously (Lara et al., 1982) by total protein concentration determined by the Lowry method.

Determination of GS activity. Cell-free extracts were prepared as previously described (Lara et al., 1982: Vichido et al., 1978). GS activity was measured as described by Ferguson \& Sims (1974a). Specific activity was expressed as units (mg total protein $)^{-1}$, units being $\mu \mathrm{mol} \gamma$-glutamyl hydroxamate produced $\min ^{-1}$.

Ammonium determination. Samples of the medium were collected and ammonium was measured with an Orion electrode (Espín et al., 1979).

Determination of amino acid pools. Samples for amino acid analysis were prepared by homogenizing cells with $80 \%(\mathrm{v} / \mathrm{v})$ ethanol (Hummelt \& Mora, 1980a). The amino acids were separated in an Aminco amino acid analyser, coupled with orthophthalaldehyde (Sigma) and quantified in an Aminco Ratio Fluorometer.

Determination of other metabolites. Mycelial samples were collected on membrane filters (Millipore, type HA, $0.45 \mu \mathrm{m}$ ) and washed with distilled water. Glucose, 2-oxoglutarate and other organic acids were extracted by resuspending the samples in $0.6 \mathrm{M}-\mathrm{HClO}_{4}$.

Glucose was determined with a glucose kit (Boehringer Mannheim). 2-Oxoglutarate was determined by measuring the initial rate of change in $A_{340}$, using bovine GDH. A sample of the extract was incubated at room temperature with $30 \mathrm{~mm}$-ammonium sulphate, $0.1 \mathrm{~mm}-\mathrm{NADH}$ and $0.01 \mathrm{ml}$ of a $2.5 \%(\mathrm{v} / \mathrm{v})$ solution of bovine liver GDH [50 units (mg protein) $)^{-1}$ ] (Sigma product no. G2626) in $1 \mathrm{ml}$ final volume of $100 \mathrm{~mm}$-potassium phosphate buffer $\mathrm{pH} 7.6$.

The intracellular concentration of pyruvate (Table 2) was determined by measuring the initial rate of change in $A_{340}$, using bovine lactic dehydrogenase (LDH). A sample of the extract was incubated at room temperature with $0.1 \mathrm{~mm}-\mathrm{NADH}$ and $0.01 \mathrm{ml}$ of a $2.5 \%(\mathrm{v} / \mathrm{v})$ solution of $\mathrm{LDH}$ [ 400 units (mg protein) ${ }^{-1}$ ] (Sigma product no. L1006) in $1 \mathrm{ml}$ final volume of $100 \mathrm{mM}$-Tris buffer $\mathrm{pH} 7.8$.

To measure the $\mathrm{CO}_{2}$ released from $\left[\mathrm{U}-{ }^{14} \mathrm{C}\right]$ sucrose, samples of the culture were taken and transferred to a sidearm tube with fresh medium containing $0.06 \%$ sucrose. These cultures received a 15 min pulse with $\left[\mathrm{U}^{-14} \mathrm{C}\right]$ sucrose $\left(0.5 \mu \mathrm{Ci} \mathrm{ml}^{-1} ; 18.5 \mathrm{kBq} \mathrm{ml}^{-1}\right)$. The $\mathrm{CO}_{2}$ released was collected with $\mathrm{NaOH}$ (Mora et al., 1972). The same procedure was followed to determine the $\mathrm{CO}_{2}$ released from $\left[6^{-14} \mathrm{C}\right] \mathrm{glucose}$; in this case the fresh medium contained $0.3 \%$ glucose and $\left[6-^{-14} \mathrm{C}\right]$ glucose $\left(0.5 \mu \mathrm{Ci} \mathrm{ml}^{-1} ; 18.5 \mathrm{kBq} \mathrm{ml}^{-1}\right)$.

Measurement of radioactivity incorporated into 2-oxoglutarate from $\left[U-{ }^{14} \mathrm{C}\right]$ sucrose. Cultures were labelled for $15 \mathrm{~min}$ with [U-14 ${ }^{14}$ ]sucrose at $25 \mu \mathrm{Ci} \mathrm{ml}^{-1}$ in $2 \mathrm{ml}$ medium with the indicated nitrogen source and $0.06 \%$ sucrose as carbon source. 2-Oxoglutarate was extracted as described above, and was completely converted to glutamate using $0.1 \mathrm{ml}$ of a $2.5 \%(\mathrm{v} / \mathrm{v})$ solution of bovine liver GDH [50 units (mg protein) $\left.)^{-1}\right]$ (Sigma: as above) and $60 \mathrm{~mm}$ NADH in $100 \mathrm{~mm}$-potassium phosphate buffer $\mathrm{pH} 7.6$. The reaction was left for $40 \mathrm{~min}$ at room temperature and stopped with $80 \%(\mathrm{v} / \mathrm{v})$ ethanol. The precipitated protein was separated by centrifugation and the supernatant, containing the amino acids and oxo acids, was lyophilized and resuspended in $150 \mu$ l lithium citrate buffer $\left(0.30 \mathrm{M}-\mathrm{Li}^{+}, 0.053 \mathrm{M}\right.$-citrate, $\left.\mathrm{pH} 2.88\right)$ (Benson Co., Reno, Nev., USA; product no. 1216). The amino acids were seperated in an Aminco amino acid analyser and the fractions corresponding to glutamate were collected and counted in a liquid scintillation counter. Radioactivity specifically incorporated to 2-oxoglutarate was determined by subtracting the radioactivity incorporated into glutamate in a control without GDH from that incorporated when GDH was added.

Measurement of radioactivity incorporated into tricarboxylic acid cycle intermediates from $\left[U-{ }^{14} \mathrm{C}\right]$ sucrose. Cultures were labelled for $15 \mathrm{~min}$ with $\left[\mathrm{U}-{ }^{-14} \mathrm{C}\right]$ sucrose at $25 \mu \mathrm{Ci} \mathrm{ml}^{-1}$ in $2 \mathrm{ml}$ medium with the indicated nitrogen source and $0.06 \%$ sucrose as the carbon source. The mycelia were collected and the organic acids were extracted as described above. The extracts containing the organic acids were stored at $4{ }^{\circ} \mathrm{C}$ before separation and quantification of the tricarboxylic acid cycle intermediates by HPLC (J. Calderón and co-workers, unpublished). The fractions corresponding to the elution time of each tricarboxylic acid cycle intermediate were collected and their radioactivity was measured in a liquid scintillation counter. 
Measurement of radioactivity incorporated into amino acids from $\left[\mathrm{U}^{14} \mathrm{C}\right]$ sucrose. Cultures were labelled for $15 \mathrm{~min}$ with $\left[\mathrm{U}^{-14} \mathrm{C}\right]$ sucrose at $100 \mu \mathrm{Ci} \mathrm{ml}{ }^{-1}$ in $1 \mathrm{ml}$ medium with the indicated nitrogen source and $0.06 \%$ sucrose as the carbon source. The mycelia were collected and the amino acid content was determined as described by Hummelt \& Mora $(1980 a)$. The radioactivity incorporated into each amino acid was determined in a liquid scintillation counter.

Reproducibility of results. The experiments reported were each repeated at least once; representative results are shown.

\section{RESULTS}

\section{Glutamine synthesis and carbon metabolism}

The experimental approach used to study whether glutamine synthesis and carbon metabolism were coordinately regulated consisted in inhibiting glutamine synthesis and determining whether sucrose catabolism was also impaired. For this purpose we used mutant strains of $N$. crassa which had a low ammonium assimilation capacity, so as to make it easier to achieve a drastic inhibition of carbon and nitrogen flows.

The $\mathrm{GDH}^{-}$mutant strain has a residual growth on ammonium as nitrogen source (Fincham, 1950 ) due to the synthesis of glutamate by GOGAT (Hummelt \& Mora, 1980a, $b$ ). In these circumstances both 2-oxoglutarate [32 nmol (mg protein) $\left.{ }^{-1}\right]$ and ammonium (Fincham, 1950), substrates of GDH, accumulate intracellularly as a result of the partial block of glutamate synthesis. When glycine or serine is added to the medium, the growth of the GDH ${ }^{-}$mutant is totally arrested (Fincham, 1950). These amino acids are inhibitors of GS from several sources (Stadtman \& Ginsburg, 1974). They are effective inhibitors of $N$. crassa GS activity in vitro at low glutamate concentrations and they also inhibit glutamine synthesis in vivo (Hernández et al., 1986). We explain the complete blockage of growth on ammonium of the $\mathrm{GDH}^{-}$mutant by glycine and serine as the result of the inhibition of glutamine synthesis in vivo. We studied the relation between glutamine synthesis and carbon catabolism from sucrose in this GDH' mutant by inhibiting GS activity with glycine and serine and determining the intracellular pools of 2oxoglutarate. After $12 \mathrm{~h}$ incubation under these conditions the intracellular pools of 2oxoglutarate in the conidia were very low : $2.8 \mathrm{nmol}(\mathrm{mg} \text { protein })^{-1}$ on ammonium plus glycine and $2.4 \mathrm{nmol}(\mathrm{mg} \text { protein })^{-1}$ on ammonium plus serine. These results indicate an inhibition of sucrose catabolism which may also contribute to the growth inhibition of the $\mathrm{GDH}^{-}$mutant by glycine and serine. The inhibitory effect of these amino acids on growth of conidia of the $\mathrm{GDH}^{-}$ mutant strain was reversible, since after $12 \mathrm{~h}$ incubation on ammonium plus an inhibitory amino acid the conidia were able to grow on ammonium as the sole nitrogen source (data not shown). To see whether the decreased 2-oxoglutarate content was specifically related to the inhibition of GS by glycine or serine, we tried to inhibit the growth of the $\mathrm{GDH}^{-}$mutant with methionine sulphoximine (MS), a specific inhibitor of GS activity (Ronzio \& Meister, 1968). In this condition, the 2-oxoglutarate pool in the conidia was barely detectable $[0.9 \mathrm{nmol}(\mathrm{mg}$ protein $)^{-1}$. The same phenomenon was observed when growth of the wild-type strain on ammonium was inhibited with MS (data not shown). These results suggested that there could be a direct relation between glutamine synthesis and 2-oxoglutarate concentration.

The effect of the inhibition of glutamine synthesis on sucrose catabolism was directly tested by determining the synthesis of tricarboxylic acid cycle intermediates over a short period of time following transfer of previously grown mycelia of the $\mathrm{GDH}^{-}$mutant to ammonium or ammonium plus an inhibitor of GS (glycine or MS) (Table 1). At this time there was a very small difference in growth between each culture and the intracellular glucose content was similar in every condition (data not shown). The specific radioactivity of the tricarboxylic acid cycle intermediates, 2-oxoglutarate, pyruvate, succinate and malate, was lower in mycelium incubated on ammonium plus either glycine or MS; the effect was more apparent in the presence of glycine (Table 1).

These experiments indicate that the inhibition of glutamine synthesis prevents sucrose catabolism at the level of synthesis of the tricarboxylic acid cycle intermediates. 
Table 1. Synthesis of tricarboxylic acid cycle intermediates in vivo in the $G D H^{-}$mutant

Cultures were grown for $12 \mathrm{~h}$ on glutamate and then transferred to the indicated nitrogen source. The concentrations used were $25 \mathrm{~mm}$-ammonium, $50 \mathrm{~mm}$-glycine and $3 \mathrm{~mm}$-MS. The tricarboxylic acid cycle intermediates synthesized in vivo were quantified after $30 \mathrm{~min}$ incubation on the indicated nitrogen source; the cultures received a pulse with $\left[\mathrm{U}^{-14} \mathrm{C}\right]$ sucrose as described in Methods. The experiment was repeated three times; representative results are shown.

\begin{tabular}{lcccc} 
Nitrogen & \multicolumn{3}{c}{ Specific radioactivity (c.p.m. nmol ${ }^{-1}$ ) } \\
source & $\begin{array}{c}\text { 2-Oxo- } \\
\text { glutarate }\end{array}$ & Pyruvate & Succinate & Malate \\
$\begin{array}{c}\text { Ammonium } \\
\text { Ammonium } \\
\text { glycine }\end{array}$ & 706 & 252918 & 13016 & 419909 \\
$\begin{array}{c}\text { Ammonium } \\
\text { MS }\end{array}$ & 79 & 28598 & 3702 & ND \\
& 159 & 115978 & 10930 & 130423
\end{tabular}

ND, Not detected.

Table 2. Metabolite contents in the $G D H^{-} ; G S^{ \pm}$mutant

Conidia were incubated for $12 \mathrm{~h}$ with the indicated nitrogen sources. The amino acid concentrations used were $5 \mathrm{~mm}$-glutamine and $50 \mathrm{~mm}$-glycine, serine or leucine. The experiment was repeated twice; representative results are shown.

\begin{tabular}{|c|c|c|c|c|c|c|c|}
\hline \multirow[b]{2}{*}{$\begin{array}{l}\text { Nitrogen } \\
\text { source }\end{array}$} & \multirow{2}{*}{ 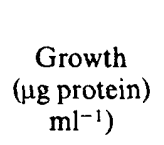 } & \multirow{2}{*}{$\begin{array}{l}\text { Ammonium } \\
\text { released } \\
{[\mu \mathrm{mol}(\mathrm{mg}} \\
\left.\text { protein })^{-1}\right]\end{array}$} & \multicolumn{5}{|c|}{ Metabolite content [nmol (mg protein $\left.)^{-1}\right]$} \\
\hline & & & Glutamate & Glutamine & $\begin{array}{c}\text { 2-Oxo- } \\
\text { glutarate }\end{array}$ & Pyruvate & Glucose \\
\hline Glutamine & 321 & 6 & 136 & $\mathrm{ND}$ & 27 & 23 & 26 \\
\hline $\begin{array}{l}\text { Glutamine + } \\
\text { glycine } \\
\text { Glutamine }+\end{array}$ & 2 & 23 & 33 & 141 & 3 & 3 & 78 \\
\hline $\begin{array}{l}\text { serine } \\
\text { Glutamine }+ \\
\text { leucine }\end{array}$ & $77^{*}$ & 16 & 152 & $\begin{array}{l}422 \\
279\end{array}$ & $\begin{array}{r}5 \\
15\end{array}$ & 3 & $\begin{array}{l}85 \\
10\end{array}$ \\
\hline
\end{tabular}

ND, Not detected.

*There was optimal growth, after an initial lag phase.

\section{Glutamine recycling and carbon metabolism}

Glutamine is a very good nitrogen source in $N$. crassa (Vichido et al., 1978). However, mutants lacking some of the ammonium assimilation related enzyme activities, e.g. $\mathrm{GDH}^{-}$, $\mathrm{GOGAT}^{-} ; \mathrm{GDH}^{-}$, and $\mathrm{GDH}^{-} ; \mathrm{GS}^{ \pm}$strains, have a slower growth rate and/or excrete ammonium into the medium when glutamine is used as nitrogen source (Calderón et al., 1985; Calderón \& Mora, 1985). This phenomenon is explained by the reduced capacity of the mutants to assimilate ammonium derived from glutamine degradation, thus indicating recycling of glutamine (Calderón \& Mora, 1985).

Arrest of growth on ammonium when glutamine synthesis was inhibited was to be expected; however, as the inhibition of glutamine synthesis also affected carbon catabolism from sucrose (Table 1) this could be a sufficient condition for the inhibition of growth even with glutamine present. The latter assumption was investigated was investigated by using the double mutant $\mathrm{GDH}^{-} ; \mathrm{GS}^{ \pm}$, which has a low synthesis of both glutamate and glutamine, so that maximal inhibition of glutamine synthesis by glycine or serine could be achieved: these amino acids very effectively inhibit the $N$. crassa GS activity in vitro when glutamate concentration is low (Hernández et al., 1986).

When glutamine was the sole nitrogen source, the culture grew optimally and excreted ammonium into the medium, and the glutamine pool was undetectable (Table 2). We interpret 
Table 3. Synthesis of tricarboxylic acid cycle intermediates in vivo and $\mathrm{Co}_{2}$ release in the wild-type and $G S^{ \pm}$mutant strains grown on glutamine

Cultures were pregrown for $12 \mathrm{~h}$ on $5 \mathrm{~mm}$-glutamate and then transferred to $5 \mathrm{~mm}$-glutamine. The tricarboxylic acid cycle intermediates synthesized in vivo and $\mathrm{CO}_{2}$ released from sucrose were quantified after 30 min incubation on glutamine; the cultures received a pulse with [U-14 C]sucrose as described in Methods. The experiment was repeated twice; representative results are shown.

\begin{tabular}{lccccc} 
& \multicolumn{2}{c}{ Specific radioactivity (c.p.m. nmol-1) } & & $\begin{array}{c}\mathrm{CO}_{2} \text { from sucrose } \\
\text { [c.p.m. (mg protein) }\end{array}$ \\
\cline { 2 - 5 } & $\begin{array}{c}\text { 2-Oxo- } \\
\text { glutarate }\end{array}$ & Pyruvate & Succinate & Malate & (m) \\
Wild-type & 1798 & 75075 & 19563 & 3527315 & 23520 \\
GS $^{ \pm}$mutant & 96 & 16038 & 1813 & 69185 & 9137
\end{tabular}

the latter as being the result of the degradation of glutamine when the cells were grown on this amino acid as nitrogen source and of the very low capacity of the $\mathrm{GDH}^{-} ; \mathrm{GS}^{ \pm}$mutant to reassimilate ammonia and to synthesize glutamine. In the presence of glutamine plus glycine or serine, the growth of the $\mathrm{GDH}^{-} ; \mathrm{GS}^{ \pm}$mutant was completely abolished, and the non-growing conidia excreted more ammonium in proportion to their protein content than did the mycelium growing on glutamine alone (Table 2). Under these conditions, a decrease in intracellular glutamate and a large increase in intracellular glutamine were observed (Table 2). The increase in glutamine was probably due to accumulation from the medium after $12 \mathrm{~h}$ incubation in the absence of growth.

In this experiment leucine was used as a control because it competes with glutamine uptake in a similar way to the inhibitory amino acids (Pall, 1969) without inhibiting GS activity. In our conditions, glutamine uptake was lower in the presence of either glycine, serine or leucine than with glutamine alone (data not shown). When leucine was added to the medium together with glutamine, the $\mathrm{GDH}^{-} ; \mathrm{GS}^{ \pm}$mutant was able to grow after a lag phase; its excretion of ammonium was barely detectable and it had high intracellular pools of glutamate and glutamine (Table 2).

When the $\mathrm{GDH}^{-} ; \mathrm{GS}^{ \pm}$mutant was incubated on glutamine plus glycine or serine, the intracellular pools of pyruvate and 2-oxoglutarate in the inhibited conidia were very low as compared to those found in conidia germinating on glutamine alone or on glutamine plus leucine (Table 2). The intracellular pools of glucose were higher in the inhibited conidia incubated on glutamine plus glycine or serine than in those incubated on glutamine plus leucine or glutamine alone (Table 2). This indicates that the low pools of 2-oxoglutarate and pyruvate found on glutamine plus glycine or serine (Table 2) were not due to the lack of glucose. Another observation consistent with 2-oxoglutarate deficiency being responsible for the low glutamate content was the presence of a high activity of a glycine :2-oxoglutarate transaminase (data not shown), which could provide intracellular glutamate whenever glycine and 2-oxoglutarate were present.

The growth-inhibitory effect of glycine and serine on the $\mathrm{GDH}^{-} ; \mathrm{GS}^{ \pm}$mutant strain incubated on glutamine was reversible, since the conidia were able to grow if the inhibitors were removed after $12 \mathrm{~h}$.

We conclude that glutamine synthesis was required for growth even in the presence of this amino acid as the nitrogen source, since the inhibitory effect of glycine and serine on growth of the $\mathrm{GDH}^{-} ; \mathrm{GS}^{ \pm}$mutant correlated with a deficiency of pyruvate, 2-oxoglutarate and glutamate, and not with glutamine limitation (Table 2).

The data presented in Table 2 lead us to propose that glutamine synthesis, rather than a particular absolute glutamine content, is necessary for optimal utilization of the carbon source, and that glutamine cycling is a necessary condition for growth even in the presence of glutamine. To obtain further support for this proposition, we measured sucrose catabolism in the presence of glutamine in the wild-type strain as compared to the $\mathrm{GS}^{ \pm}$mutant, which has a single mutation that alters the structure of the GS $\beta$ polypeptide (Dávila et al., 1983), has a 20-fold lower GS 


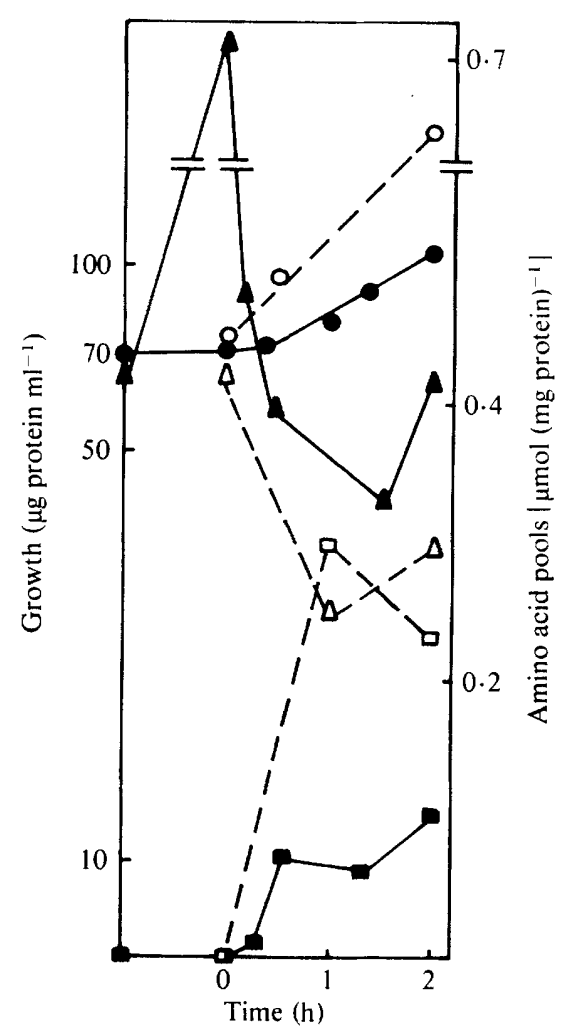

Fig. 1. Growth and amino acid pools of the GS ${ }^{ \pm}$mutant. The culture was grown for $12 \mathrm{~h}$ on $5 \mathrm{mm-}$ glutamate and then the mycelium was washed and divided into two cultures. One culture (open symbols) was transferred to $5 \mathrm{~mm}$-glutamine, at time 0 . The other culture (filled symbols) was first incubated for $1 \mathrm{~h}$ in a medium without a nitrogen source and with $0.3 \mathrm{mM}-\mathrm{MS}$, then washed and transferred to $5 \mathrm{~mm}$-glutamine. $\bigcirc, \bigcirc$, Growth; $\triangle, \boldsymbol{\Lambda}$, intracellular glutamate; $\square, \square$, intracellular glutamine. The experiment was repeated at least three times; representative results are shown.

activity than the wild-type and is able to grow on glutamate at $37^{\circ} \mathrm{C}$ (Dávila et al., 1978). The synthesis of tricarboxylic acid cycle intermediates in vivo and the $\mathrm{CO}_{2}$ released from sucrose were measured $30 \mathrm{~min}$ after transfer of previously grown mycelia of the two strains from glutamate to glutamine as the nitrogen source, where their growth rate was similar. The specific radioactivity of 2-oxoglutarate, pyruvate, succinate and malate was higher in the wild-type than in the GS \pm mutant strain when grown on glutamine (Table 3). In addition, the $\mathrm{CO}_{2}$ released from $\left[\mathrm{U}^{-14} \mathrm{C}\right]$ sucrose was lower in the GS ${ }^{ \pm}$mutant, whose synthesis of glutamine is lower. This effect was not due to a dilution of the label by glucose accumulation, since the total intracellular glucose content was $3 \cdot 6$-fold higher in the wild-type than in the GS ${ }^{ \pm}$mutant. The synthesis of glutamate was similar in both strains (data not shown). We propose that when glutamine synthesis is lower due to the partial block on GS activity in the GS ${ }^{ \pm}$mutant strain, carbon catabolism is impaired at the level of the synthesis of intermediates of the tricarboxylic acid cycle, reflected in a diminution of $\mathrm{CO}_{2}$ released from sucrose (Table 3).

This proposal was further tested under conditions of maximal inhibition of GS activity. This was achieved by adding MS to the GS \pm mutant, thus reducing the GS activity 150 -fold as compared to that in the wild-type strain. Since MS is an irreversible inhibitor of GS (Ronzio \& Meister, 1968), the GS activity was still inhibited $2 \mathrm{~h}$ after removal of the inhibitor (Table 4); activity was regained after $4 \mathrm{~h}$ as a result of enzyme synthesis (data not shown). The results of these experiments are shown in Fig. 1 and Table 4. In the presence of MS, no glutamine pool was detected and the glutamate pool increased (Fig. 1). When this culture was shifted to glutamine, it 
Table 4. GS activity, synthesis of glutamine, glutamate and 2-oxoglutarate in vivo and $\mathrm{CO}_{2}$ release from glucose in the $G S^{ \pm}$strain

After $12 \mathrm{~h}$ growth on $5 \mathrm{~mm}$-glutamate the culture was washed and transferred to $5 \mathrm{~mm}$-glutamine for $2 \mathrm{~h}$ (a) or to $0.5 \mathrm{~mm}$-MS for $1 \mathrm{~h}$ followed by washing and transfer to $5 \mathrm{~mm}$-glutamine for $2 \mathrm{~h}(b)$. All the parameters shown were measured after $2 \mathrm{~h}$ growth on glutamine. The experiment was repeated at least three times; representative results are shown.

\begin{tabular}{|c|c|c|c|c|c|}
\hline Condition & $\begin{array}{c}\text { GS specific } \\
\text { activity } \\
{\left[\mathrm{U}(\mathrm{mg} \text { protein })^{-1}\right]}\end{array}$ & $\begin{array}{c}\text { Glutamine } \\
\text { from sucrose } \\
\text { (c.p.m. } \mu \mathrm{mol}^{-1} \text { ) }\end{array}$ & $\begin{array}{c}\text { Glutamate } \\
\text { from sucrose* } \\
\text { (c.p.m. } \mu \mathrm{mol}^{-1} \text { ) }\end{array}$ & $\begin{array}{l}\text { 2-Oxoglutarate from } \\
\text { sucrose* [c.p.m. } \\
\left.\text { (mg protein })^{-1}\right]\end{array}$ & $\begin{array}{c}\mathrm{CO}_{2} \text { from } \\
\text { glucose } \dagger[\text { c.p.m. } \\
\left.\text { (mg protein) })^{-1}\right]\end{array}$ \\
\hline $\begin{array}{l}\text { (a) } \mathrm{Gln} \\
\text { (b) } \mathrm{MS} \rightarrow \mathrm{G} \ln \end{array}$ & $\begin{array}{l}0.0030 \\
0.0004\end{array}$ & $\begin{array}{r}1225 \\
163\end{array}$ & 5650 & $\begin{array}{r}2124 \\
325\end{array}$ & $\begin{array}{l}4593 \\
1652\end{array}$ \\
\hline
\end{tabular}

* The cultures received a pulse of $\left[\mathrm{U}-{ }^{14} \mathrm{C}\right]$ sucrose.

$\dagger$ Different cultures received a pulse of $\left[6^{-14} \mathrm{C}\right] \mathrm{glucose}$.

had an initial lag phase that was followed by a slower growth despite its high glutamate content and sizeable glutamine pool (Fig. 1) as compared to the non-inhibited culture. Although the glutamine content was only 2-fold lower in the inhibited culture (Fig. 1) the glutamine synthesis varied $7 \cdot 5$-fold. We measured the carbon catabolism of sucrose after the shift to glutamine. The amount of $\mathrm{CO}_{2}$ released from $\left[6-{ }^{14} \mathrm{C}\right]$ glucose was lower when the GS was inhibited and a correlation with a decrease in 2-oxoglutarate synthesis from sucrose was also apparent (Table 4). This was supported by the lower glutamate synthesis observed when GS was inhibited (Table 4).

\section{DISCUSSION}

In this work we explored the relation between glutamine synthesis and carbon catabolism from sucrose. By using mutant strains $\left(\mathrm{GDH}^{-}, \mathrm{GS}^{ \pm}\right.$and the double mutant $\left.\mathrm{GDH}^{-} ; \mathrm{GS}^{ \pm}\right)$with a reduced ability to assimilate ammonium through glutamate, and glutamine and/or GS inhibitors, nitrogen and carbon metabolism were both blocked.

When mycelium of the $\mathrm{GDH}^{-}$mutant was incubated on ammonium plus an inhibitor of GS, sucrose catabolism decreased as shown by a lower synthesis of several tricarboxylic acid cycle intermediates (Table 1). This effect was observed after a short period of time during which growth was not affected. Since both glycine, which inhibits GS activity (Stadtman \& Ginsburg, 1979; Hernández et al., 1986), and MS, which is a specific GS inhibitor (Ronzio \& Meister, 1968), gave the same effect (Table 1) we propose that the diminution in carbon catabolism was an effect specifically related to the inhibition of glutamine synthesis.

A relevant finding was that the inhibition of glutamine synthesis was sufficient to inhibit growth even in the presence of glutamine. We observed that with the $\mathrm{GDH}^{-} ; \mathrm{GS}^{ \pm}$mutant on glutamine plus a GS inhibitory amino acid, growth was completely arrested and the intracellular levels of 2-oxoglutarate and pyruvate were low (Table 2). On glutamine plus leucine, not a GS inhibitor, there was a minor effect on the content of tricarboxylic acid cycle intermediates (Table 2). This can be explained by the lag phase that precedes growth under these conditions, and may also explain the glutamine accumulation (Table 2). In addition, the presence of the inhibitors was not essential since an impairment of sucrose catabolism was also observed in mycelia of a partial glutamine auxotroph $\left(\mathrm{GS}^{ \pm}\right)$growing on glutamine as the sole nitrogen source (Table 3 ).

The effect of inhibiting glutamine synthesis was further enhanced when MS, an inhibitor of GS activity, was added to the GS ${ }^{ \pm}$mutant in the presence of glutamine (Table 4, Fig. 1). Under these conditions a higher inhibition of GS activity was observed, with a consequent decrease in synthesis of glutamine, glutamate, and 2-oxoglutarate from sucrose and $\mathrm{CO}_{2}$ release from [6${ }^{14} \mathrm{Clglucose}$ (Table 4). The outcome was a low growth rate in the presence of a sizeable intracellular glutamine pool (Fig. 1).

These data thus support our conclusion that growth inhibition is not due to a lack of glutamine content. We have reported (Hernández et al., 1986) that when growth and GS were inhibited by 
glycine in the GS ${ }^{ \pm}$mutant in the presence of glutamate, the synthesis of glutamine in vivo was 100 -fold lower while the absolute glutamine content was only 2-fold lower as compared to the culture growing on glutamate.

The data presented in this work indicate that in $N$. crassa there is coordinated regulation of carbon and nitrogen source utilization, i.e. when nitrogen assimilation was blocked through the inhibition of glutamine synthesis, carbon catabolism from sucrose decreased. This may explain the necessity for glutamine cycling (Calderón et al., 1985; Calderón \& Mora, 1985). The drain of ATP through glutamine synthesis and the regulation of carbon metabolism by energy charge could be considered as a point of interaction in the coordinated regulation of carbon and nitrogen metabolism. An observation consistent with this proposition was that in $N$. crassa the intracellular concentrations of ATP were raised when glutamine synthesis was inhibited $(\mathrm{G}$. Hernández and co-workers, unpublished). It has been reported (Wohlhueter et al., 1973) that when ammonium is added to an ammonium-limited culture of Escherichia coli there is a burst of glutamine synthesis which imposes a drastic drain on ATP; the accumulated glutamine activates the enzymes for GS inactivation by adenylylation and thus the ATP pool is replenished. These data suggest that the amount of ATP spent in glutamine synthesis may be important to the cell. The control of glycolysis and respiration by energy charge is well documented (Atkinson, 1977). We propose that whenever glutamine synthesis is blocked the energy status of the cell improves with the consequent inhibition of carbon catabolism. This coordinated regulatory mechanism could allow the cell to avoid the accumulation of carbon skeletons when synthesis of the universal nitrogen donors is blocked.

We are grateful to Jorge Calderón, Rafael Palacios and Lorenzo Segovia for critically reviewing the manuscript and to Gisela Du Pont and Martha Albores for technical assistance. This work was supported in part by a grant from Consejo Nacional de Ciencia y Tecnología (CONACyT) México.

\section{REFERENCES}

Atkinson, D. (1977). Cellular Energy Metabolism and its Regulation. New York: Academic Press.

Calderón, J. \& MORA, J. (1985). Glutamine cycling in Neurospora crassa. Journal of General Microbiology 131, 3237-3242.

Calderón, J., Morett, E. \& Mora, J. (1985). The $\omega$ amidase pathway in the degradation of glutamine in Neurospora crassa. Journal of Bacteriology 161, 807809.

Dávila, G., Sánchez, F., Palacios R. \& Mora, J. (1978). Genetics and physiology of Neurospora crassa glutamine auxotrophs. Journal of Bacteriology 134, 693-698.

Dávila, G., Lara, M., Guzmán, J. \& Mora, J. (1980). Relation between structure and function of Neurospora crassa glutamine synthetase. Biochemical and Biophysical Research Communications 92, 134-140.

Dávila, G., Brom, S., Mora, Y., Palacios, R. \& MorA, J. (1983). Genetic and biochemical characterization of glutamine synthetase from Neurospora crassa glutamine auxotrophs and their revertants. Journal of Bacteriology 156, 993-1000.

Espín, G., Palacios, R. \& Mora, J. (1979). Glutamine metabolism in nitrogen-starved conidia of Neurospora crassa. Journal of General Microbiology 115, 5968.

FERguson A. R. \& SimS, A. P. (1974a). The regulation of glutamine metabolism in Candida utilis: the role of glutamine in the control of glutamine synthetase. Journal of General Microbiology 80, 159-171.

FERGuson, A. R. \& Sims, A. P. (1974b). The regulation of glutamine metabolism in Candida utilis: the inactivation of glutamine synthetase. Journal of General Microbiology 80, 173-185.

FinchaM, J. R. S. (1950). Mutant strains of Neurospora deficient in aminating ability. Journal of Biological Chemistry 181, 61-73.

Hemmings, B. A. (1978). Evidence for the degradation of nicotinamide adenine dinucleotide phosphatedependent glutamate dehydrogenase of Candida utilis during rapid enzyme inactivation. Journal of Bacteriology 133, 867-877.

Hernández, G., Sánchez-Pescador, R., Palacios, R. \& MORA, J. (1983). Nitrogen source regulates glutamate dehydrogenase NADP synthesis in Neurospora crassa. Journal of Bacteriology 154, 524-528.

Hernández, G., Mora, Y. \& Mora, J. (1986). Regulation of glutamine synthesis by glycine and serine in Neurospora crassa. Journal of Bacteriology 165, 133-138.

Hummelt, G. \& MORA, J. (1980a). NADH-dependent glutamate synthase and nitrogen metabolism in Neurospora crassa. Biochemical and Biophysical Research Communications 92, 127-133.

HummelT, G. \& MORA, J. (1980 $b$ ). Regulation and function of glutamate synthase in Neurospora crassa. Biochemical and Biophysical Research Communications 96, 1688-1694.

KaPOOR, M. \& Grover, A. K. (1970). Catabolitecontrolled regulation of glutamate dehydrogenases of Neurospora crassa. Canadian Journal of Microbiology 16, 33-40.

lara, M., Blanco, L., Campomanes, M., Calva, E., Palacios, R. \& MORA, J. (1982). Physiology of 
ammonium assimilation in Neurospora crassa. Journal of Bacteriology 150, 105-112.

MORA, J., SAlCEda, R. \& SÁNChez, S. (1972). Regulation of arginase activity by intermediates of the arginine biosynthetic pathway in Neurospora crassa. Journal of Bacteriology 110, 870-877.

Mora, Y., Chávez, O. \& Mora, J. (1980). Regulation of Neurospora crassa glutamine synthetase by carbon and nitrogen source. Journal of General Microbiology 118, 455-463.

PALl, M. L. (1969). Amino acid transport in Neurospora crassa. I. Properties of two amino acid transport systems. Biochimica et biophysica acta 203, 139-149.

Quinto, C., Mora, J. \& Palacios, R. (1977). Neurospora crassa glutamine synthetase. Role of enzyme synthesis and degradation on the regulation of enzyme concentration during exponential growth. Journal of Biological Chemistry 252, 8724-8727.

RONZIO, R. \& MEISTER, A. (1968). Phosphorylation of methionine sulfoximine by glutamine synthetase. Proceedings of the National Academy of Sciences of the United States of America 59, 164-170.
Sánchez, F., Campomanes, M., Quinto, C., HansBERG, W., Mora, J. \& PAlacios, R. (1978). Nitrogen source regulates glutamine synthetase mRNA levels in Neurospora crassa. Journal of Bacteriology 136, 880-885.

Stadtman, E. R. \& Ginsburg, A. (1974). The glutamine synthetase of Escherichia coli: structure and control. In The Enzymes, vol. 10, pp. 755-807. Edited by P. D. Boyer. New York: Academic Press. Vichido, I., Mora, Y., Quinto, C., Palacios, R. \& MORA, J. (1978). Nitrogen regulation of glutamine synthetase in Neurospora crassa. Journal of General Microbiology 106, 251-259.

VoGEL, H. J. (1964). Distribution of lysine pathways among fungi: evolutionary implications. American Naturalist 98, 435-446.

WOHLhUeter, R. M., Schutt, M. \& Holzer, H. (1973). Regulation of glutamine synthesis in vivo in Escherichia coli. In The Enzymes of Glutamine Metabolism, pp. 45-64. Edited by S. Prusiner \& E. R. Stadtman. New York: Academic Press. 